\title{
Coverage of neuroma in continuity
}

\author{
Roberto Adani \\ From 10th Congress of the Asia-Pacific Federation of Societies of Surgery fo the Hand and the 6th Congress \\ of Asia-Pacific Federation of Societies of Hand Therapists \\ Kuala Lumpur, Malaysia. 2-4 October 2014
}

Neurogenic pain can develop after microsurgical repair of a median nerve injury or when the lesion is underestimated and therefore not treated at all. Nerve injury with neuromatous pain may be associated with tumefaction at the wrist, increased pain and tingling when tapped [1]. The aim of the treatment is to both minimize pain and preserve residual function of the median nerve.

Surgical procedures such as neurolysis do not always relieve the patients' pain. Reconstruction with grafts is reserved only for cases with very poor sensory and motor recovery. Neurolysis should be performed carefully to avoid devascularization of the nerve and formation of a new scar around the nerve [2]. Particular attention has been given to the coverage and wrapping of a neuroma with different pedicle flaps as the pronator quadratus muscle flap [3], the Becker flap [4], the reverse island radial fascial flap with or without inclusion of the radial artery [2,5-7] and the local synovial flap [8]. With regards to free flaps, Wintsch [9] believes that a thin flap of gliding fascia is the ideal flap to cover a nerve, whereas Jones [10] advocates the use of a small hemi-latissimus dorsi muscle flap. The lateral arm flap $[2,11,12]$ and the scapular flap $[2,11]$ represent other options but the thickness of the subcutaneous tissue and the overlying skin often produce very prominent flaps [10]. Goitz and Steichen [13] reported the coverage of a scarred median nerve with a free omental flap.

The purpose of this study is to review the treatment of painful neuroma of the median nerve at the wrist treated with external neurolysis and coverage using the ulnar artery perforator adipofascial flap (UAPAF) or the radial artery perforator adipofascial flap (RAPAF).

\footnotetext{
Department of Hand Surgery, Azienda Ospedaliera Universitaria Integrata
} Verona, Verona, 37134, Italy

\section{Surgical technique}

External neurolysis of the median nerve was performed in every patient. Neurolysis was done under microscopic magnification to avoid nerve damage.

\section{Ulnar artery perforator adipofascial flap}

This flap is supplied by the dorsal branch of the ulnar artery. This artery is located on a line drawn between the pisiform bone and the medial epicondyle and originates $4 \mathrm{~cm}$ proximally to the pisiform bone [4]. The location of the dorsal branch of the ulnar artery is usually confirmed by Doppler sonography [14]. This is a constant artery with a diameter of 1 to $1.3 \mathrm{~mm}$ passing beneath the flexor carpi ulnaris (FCU) tendon [4,15-17]. The artery runs in an oblique line from the volar to the dorsoulnar surface of the distal forearm [15]. The artery divides into descending and ascending branches; the latter is responsible for the vascularization of the UAPAF $[18,19]$ which measures up to $5-9 \mathrm{~cm}$ in width and $10-20 \mathrm{~cm}$ in length $[15,16,18,19]$.

An incision is performed around the wrist crease in an ulnar direction to allow neurolysis of the median nerve and it is then continued proximally along the mid-lateral ulnar border of the forearm for $10-12 \mathrm{~cm}$. The adipofascial flap is centred over the ulnar artery on the line joining the pisiform and the medial epicondyle. Thin skin flaps are carefully elevated to allow some fat to remain on the undersurface of the dermis. The subcutaneous tissue is exposed leaving part of the superficial venous plexus with the adipofascial flap. Flap elevation is begun by incising the subcutaneous tissue through the deep fascia along the radial border of the exposure, avoiding njury to the median nerve and its palmar cutaneous ch. The ulnar artery is exposed by gentle retraction of the flap. The artery is dissected away from the flap along its course proximal to the location of the dorsal branch of the ulnar artery. When the flap reaches a suitable length (10-12 cm from the wrist) it is cut proximally 
and along the ulnar side; usually the width of the flap is from 4 to $6 \mathrm{~cm}$. The flap is dissected proximally to distally in continuity with the underlying fascia. When the dissected flap is $4 \mathrm{~cm}$ proximal to the wrist joint dissection is interrupted to verify the presence and the precise location of the dorsal branch of the ulnar artery and its associated veins. Ulnar retraction of the FCU permits identification of the perforator. While identifying the dorsal branch of the ulnar artery, attention is paid to the dorsal cutaneous branch of the ulnar nerve that may be encountered during this phase [15]. Usually the pivot point of the flap is localized $4 \mathrm{~cm}$ proximal to the pisiform bone [16]. The adipofascial flap is turned over by $180^{\circ}$ and finally anchored with a few absorbable stitches around the median nerve and the skin is loosely sutured.

\section{Radial artery perforator adipofascial flap}

The flap is supplied by the septocutaneous perforators of the distal radial artery $[5,20,21]$. The radial artery at the distal forearm emerges in the septum between the flexor carpi radialis (FCR) and the brachioradialis tendons to give about 10 small perforating vessels with an external diameter between 0.3 and $0.9 \mathrm{~mm}$ [20-24]. These vessels arise approximately $1.5 \mathrm{~cm}$ proximally to the radial styloid and recur proximally at intervals of 0.4 to $1.5 \mathrm{~cm}$ [21]. A very rich venous plexus is accompanying this arterial network. For most authors the safest pivot point of the pedicle is about 2 to $4 \mathrm{~cm}$ above the radial styloid process $[20,23,24]$. Doppler examination would be useful to identify the radial artery perforators, but it may not be necessary given their reliability [24]

The proximal margin of the flap is located $10 \mathrm{~cm}$ distal to the elbow and the base of the flap is 2 to $4 \mathrm{~cm}$ proximal to the radial styloid process [22,23]. Flap dimensions reported in literature range from $8-12 \mathrm{~cm}$ in width and $15-20 \mathrm{~cm}$ in length $[23,24]$.

An incision is made on the wrist crease and after neurolysis of the median nerve, the incision is prolonged proximally for $10-14 \mathrm{~cm}$ along the axis of the radial artery. The skin is then carefully elevated in order to maintain some adipose tissue with the skin. In this phase the dissection is very similar for the UAPAF. The incision is deepened down to the deep fascia at the margins of the flap radially over the brachioradialis muscle and ulnarly over the FCR muscle with the width of the flap ranging from 5 to $6 \mathrm{~cm}$. The proximal margin of the flap is incised 10 to $12 \mathrm{~cm}$ proximal to the wrist. The adipofascial flap is elevated together with the deep fascia away from the radial artery leaving it intact. Dissection is carried on distally until the pivot point is reached, about 4 $\mathrm{cm}$ proximal to the radial styloid with a flap base narrowed to about 3 to $4 \mathrm{~cm}$ in width. The lateral forearm nerves, including the sensory superficial radial nerve and the lateral antebrachial cutaneous nerve, should be identified and carefully preserved so as to avoid injury and potential subsequent painful neuroma formation. In this procedure there is no need to identify the perforator vessels around the radial styloid and they should not be dissected in order to avoid damage. The flap is turned over by $180^{\circ}$ to cover the median nerve and the tourniquet is then released to visualize the blood supply of the flap.

The technique used in this study included subcutaneous fat taken with the fascial flap. This did not compromise vascularization of the skin of the forearm; moreover skin closure was done without excessive tension. This bulkier flap can cover the median nerve superficially with a padding tissue composed by the fascia and the adipose tissue wrapping the nerve deeply with the fascia only. In this way the median nerve is completely isolated from the adjacent finger flexor tendons and protected against external trauma. Pedicle perforator adipofascial flaps represent a safe and reliable procedure: they are harvested easily and quickly with an adequate blood supply with loupe magnification. In this study it was not possible to observe significant differences in terms of surgical technique or functional results between the two flaps used. It is therefore difficult to give definitive conclusions about the best flap to use: both can be done under axillary plexus block and the final decision depends on the local conditions and the surgeon's preference. We find the RAPAF procedure easier because the perforators do not require dissection. Also the RAPAF allows raising a longer, wider and thicker flap than the UAPAF.

Five out of the eight patients had complete resolution of pain after this procedure while two patients had partial resolution. This study is limited by the small number of patients. A prospective study is needed to ascertain the potential superiority of nerve coverage over other currently employed techniques. Also a larger number of patients collected from different centers using the same surgical procedures would support the validity of this approach.

\section{Published: 19 May 2015}

\section{References}

1. Elliot $D$, Sierakowski $A$ : The surgical management of painful nerves of the upper limb: a unit perspective. J Hand Surg 2011, 36(9):760-770.

2. Jones NF, Shaw WW, Katz RG, Angeles L: Circumferential wrapping of a flap around a scarred peripheral nerve for salvage of end-stage traction neuritis. J Hand Surg Am 2002, 2(3):35-40.

3. Becker C, Gilbert A: The cubital flap. Ann Chir Main 1988, 7(2):136-142.

4. Braun RM, Rechnic M, Neill-Cage DJ, Schorr RT: The retrograde fascial forearm flap: surgical rationale, technique, and clinical application. J Hand Surg Am 1995, 20(6):915-922.

5. Tham SK, Ireland DC, Riccio M, Morrison WA: Reverse radial artery fascial flap: a treatment for the chronically scarred median nerve in recurrent carpal tunnel syndrome. J Hand Surg Am 1996, 21(5):849-854. 
6. Luchetti R, Riccio M, Papini Zorli I, Fairplay T: Protective coverage of the median nerve using fascial, fasciocutaneous or island flaps. Handchir Mikrochir Plast Chir 2006, 38(5):317-330.

7. Wulle C: The synovial flap as treatment of the recurrent carpal tunnel syndrome. Hand Clin 1996, 12(2):379-388.

8. Wintsch K, Helaly P: Free flap of gliding tissue. J Reconstr Microsurg 1986 2(3):143-151.

9. Jones NF: Treatment of chronic pain by "wrapping" intact nerves with pedicle and free flaps. Hand Clin 1996, 12(4):765-772.

10. Dahlin LB, Lekholm C, Kardum P, Holmberg J: Coverage of the median nerve with free and pedicled flaps for the treatment of recurrent severe carpal tunnel syndrome. Scand J Plast Reonstr Surg Hand Surg 2002, 36(3):172-176.

11. Krishnan KG, Pinzer T, Schackert G: Coverage of painful peripheral nerve neuromas with vascularized soft tissue: method and result. Neurosurgery 2005, 56(2 Suppl):369-378.

12. Goitz RJ, Steichen JB: Microvascular omental transfer for the treatment of severe recurrent median neuritis of the wrist: a long term follow-up. Plast Reconstr Surg 2005, 115(1):163-171.

13. Ono S, Sebastin JS, Yazaki N, Hyakusoku H, Chung KC: Clinical applications of perforator-based propeller flaps in upper limb soft tissue reconstruction. J Hand Surg Am 2011, 36(5):853-863.

14. Karacalar A, Ozcan M: Use of a subcutaneous pedicle ulnar flap to cover skin defects around the wrist. J Hand Surg Am 1998, 23(3):551-555.

15. Unal C, Ozdemir J, Hasdemir M: Clinical application of the distal ulnar artery perforator flap in hand trauma. J Reconstr Microsurg 2011 27(9):559-565.

16. Georgescu AV, Matei I, Ardelean F, Capota I: Microsurgical nonmicrovascular flaps in forearm and hand reconstruction. Microsurgery 2007, 27(5):384-394.

17. Sananpanich K, Kun Tu Y, Kraisarin J, Chalidapong P: Reconstruction of limb soft-tissue defectsusing pedicle perforator flaps with preservation of major vessels, a report of 45 cases. Injury 2008, 39(Suppl 4):55-66.

18. Page R, Chang J: Reconstruction of Hand Soft-Tissue Defects: Alternatives to the Radial Forearm Fasciocutaneous Flap. J Hand Surg Am 2006, 31(5):847-856

19. Goffin D, Brunelli F, Galbiatti A, Sammut D, Gilbert A: A new flap based on the distal branches of the radial artery. Ann Chir Main Memb Super 1992, 11(3):217-225.

20. Weinzweig N, Chen L, Chen ZW: The distally based radial forearm fasciosubcutaneous flap with preservation of the radial artery: An anatomic and clinical approach. Plast Reconstr Surg 1994, 94(5):675-684

21. Yang D, Morris SF, Tang M, Geddes CR: Reversed forearm island flap supplied by the septocutaneous perforator of the radial artery: anatomical basis and clinical applications. Plast Reconstr Surg 2003, 112(4):1012-1016.

22. Saint-Cyr M, Mujadzic M, Wong C, Hatef D, Lajoie AD, Rohrich RJ: The radial artery pedicle perforator flap: vascular analysis and clinical implications. Plast Reconstr Surg 2010, 125(5):1469-1478.

23. Ho AM, Chang J: Radial artery perforator flap. J Hand Surg Am 2010, 35(2):308-311.

24. Jeng SF, Wei FC: The distally based forearm island flap in hand reconstruction. Plast Reconstr Surg 1998, 102(2):400-406.

doi:10.1186/1753-6561-9-S3-A76

Cite this article as: Adani: Coverage of neuroma in continuity. BMC Proceedings 2015 9(Suppl 3):A76.

\section{Submit your next manuscript to BioMed Central and take full advantage of:}

- Convenient online submission

- Thorough peer review

- No space constraints or color figure charges

- Immediate publication on acceptance

- Inclusion in PubMed, CAS, Scopus and Google Scholar

- Research which is freely available for redistribution

Submit your manuscript at www.biomedcentral.com/submit 